\title{
EL PAPEL DE LA NORMA EN LA DESPERSONALIZACIÓN DEL PODER
}

El más fuerte no es nunca lo bastante fuerte para ser siempre el amo, si no transforma su fuerza en derecho y la obediencia en deber.

\section{J.J. Rousseau}

La hipocresía es el homenaje del vicio a la virtud.

\section{Anónimo}

\section{La argumentación: un enfoque de la teoría general del derecho.}

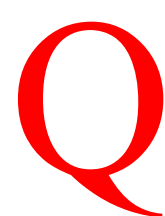

ue los abogados pasan la vida inventando, sosteniendo y rebatiendo argumentos, es un hecho que nadie discute. Cuando este hecho es visto como central en relación con todas las demás circunstancias que componen el fenómeno jurídico, tal consideración da lugar a uno de los enfoques epistemológicos que en la actualidad comparten el amplio campo iusfilosófico: el que examine el derecho como un arte, eventualmente sujeto a reglas, o bien como una creación cultural en la que pueden advertirse ciertas regularidades de hecho, clasificables y formulables al modo sociológico. Ambos matices se distinguen por la distancia o perspectiva desde la que observan el objeto: el primero parte del compromiso del sujeto cognoscente con el ámbito en el que las argumentaciones se desarrollan, en tanto el segundo describe los hechos desde una distancia mayor. ${ }^{1}$ Uno es característico del abogado práctico y del científico preocupado por la práctica profesional. El otro es propio del jurista con pretensiones de objetividad desapasionada o, como ocurre en la Argentina con la llamada teoría crítica del Derecho, del estudioso que, por hallarse ideológicamente enfrentado con las manifestaciones vigentes del poder político, busca desentrañar mecanismos que le ayuden a poner en tela de juicio este mismo poder y los métodos que emplea.

Los dos matices de este enfoque, sin embargo, comparten una misma decisión metodológica: la de identificar el derecho como un hecho social.

\footnotetext{
${ }^{1}$ La relación entre ambos se asemeja a la que observa Hart entre los puntos de vista interno y externo (cfr. Hart, H.L.A., El concepto de derecho. Buenos Aires, Abeledo-Perrot, 1963, pág. 111).
} 
Ésta es sólo una de las decisiones posibles, ya que el derecho es un fenómeno con diversas características, cada una de ellas relevante para distintos intereses. En efecto, es un lugar común en la teoría trialista (o tridimensional) sostener que el derecho es a la vez norma, hecho y valor. Alguna vez, he criticado esta teoría desde el punto de vista metodológico, ${ }^{2}$ pero la afirmación que le sirve de base es al menos apta para generar tres enfoques distintos, cada uno de los cuales privilegia un aspecto del objeto y emplea un método diferente.

Por mi parte prefiero una teoría general de corte normativista, ya que no encuentro un método apropiado para la identificación de valores trascendentes y, a su vez, una teoría del derecho que enfocase su objeto como fenómeno puramente empírico se convertiría en un segmento de la sociología. Esta actitud epistemológica, sin embargo, no implica un rechazo hacia el enfoque empirista en cualquiera de sus matices: creo, con un resabio iluminista del que no me avergüenzo, que todo conocimiento debe ser bienvenido y toda opinión examinada, aunque pienso también que tales opiniones y conocimientos deben sopesarse en relación con el cuerpo de los conocimientos ya obtenidos e integrarse, de ser posible, en un sistema general consistente que dé cuenta de unos y de otros. Pero esto último ocurre siempre en un instante posterior, ya sea por vía de simple inclusión, por medio de una ampliación y reformulación de las teorías preexistentes o por obra de una ruptura y reelaboración del marco teórico. Lo primero es, pues, la recopilación de la materia prima, ya sea proveniente de la observación, de la innovación metodológica o del puro raciocinio.

El contenido de este trabajo parte de una observación y ensaya una reflexión general a partir de ella. Ambas están referidas al ejercicio del poder por medio del derecho, pero centran su atención en un aspecto menor de este eterno drama: el del modo en que se presentan las decisiones normativas y la función que ese modo cumple en las expectativas humanas en general y en el fenómeno político en especial.

\section{Justificar y dominar, o el juego de los valores.}

Hans Kelsen dijo alguna vez que el hombre es el único animal que busca justificar sus acciones. ${ }^{3}$ Con la misma sorna podría decirse que tal afirmación peca de aventurada, ya que no podemos saber si los animales se justifican o no. Para averiguarlo tendríamos que comprender su lenguaje. Porque, ¿de qué otro nodo, sino por el lenguaje, advertimos el afán de justificación de los hombres? Las meras acciones humanas, despojadas del ropaje lingüístico que las envuelve, se mostrarían ante un observador externo como manifestaciones de la misma ternura que

${ }^{2}$ Guibourg, Ricardo A., Ghigliani, Alejandro M. y Guarinoni, Ricardo, V., Introducción al conocimiento jurídico, Buenos Aires, Astrea, 1984, págs. 196 y siguientes.

${ }^{3}$ Keisen, Hans. ¿Qué es la justicia? Buenos Aires, 1960, párrafo 13, pág. 20. 
usa una leona con sus cachorros y de la misma crueldad que emplea la fiera para sus víctimas: comer o ser comido y proteger a la propia gente parecen ser constantes de la naturaleza, y las variables consisten en qué se entienda por «comer» y «ser comido», así como con qué amplitud se asuma el concepto de «la propia gente». ${ }^{4}$

El lenguaje, en cambio, permite dar el sutil paso entre el Sein y el Sollen por medio de la construcción de proposiciones generales que se proponen como modelos de acciones valiosas o disvaliosas, elogiables, execrables o condenables. Este mecanismo permite a los hombres cierto control recíproco de las conductas.

Es claro que quien tenga mayor posibilidad de enunciar, difundir o inculcar tales modelos tiene mejor perspectiva de lograr sus propósitos. Y, a partir de esta comprobación, aparece una conclusión que muchos encuentran seductora: los valores, las normas, la moral, el derecho, la religión, el universo entero de los modelos y hasta el método científico no son más que instrumentos de dominio y aherrojamiento heterónomo, armas de unos hombres contra otros, de una clase contra las demás, de un paradigma contra la libertad creadora de los talentos rebeldes.

Tal conclusión no es falsa (¿dónde hay un pensamiento absolutamente falso?): sólo es exagerada. Los que ejercen el poder no siempre pueden emplear tales herramientas a su gusto: la religión tiene vocación de eternidad; los valores se presentan como atemporales, aun cuando se relativicen entre sí; la moral evoluciona con lentitud; los modelos no duran menos de una generación y el método científico acaba siempre por contrastarse con resultados observables. Sólo el derecho responde dócilmente a la voluntad de los poderosos, pero aun así se ven estos precisados a justificarse (es decir, a apelar a otros factores de persuasión), ya que las bayonetas, como decía Bonaparte, no sirven para sentarse sobre ellas. Y justificarse implica, entonces, ajustar el propio ejercicio del poder, real o fingidamente, a valores que el poderoso no ha podido (al menos todavía) modelar a su voluntad.

De allí que la justificación sea una herramienta indispensable del dominio, pero constituya a la vez un flanco débil de quien lo ejerce. Un flanco que lo hace pasible de crítica, blanco de la agitación, víctima de las rebeliones (pacíficas o no); reacciones todas ellas fundadas, de un modo o de otro, en los mismos principios que el poderoso trató antes de poner a su servicio.

Esta dúplice relación entre el poder y la justificación impone, en consecuencia, la práctica del disimulo. Los valores son el espejo en el que nuestras acciones se miran, e imponen respeto desde dentro mismo de nuestros temores. Naturalmente, no es lo mismo respetar que cumplir; pero para esto (entre otras cosas) está el lenguaje: para presentar nuestras acciones de tal suerte que al menos parezcan acordes con los principios

${ }^{4}$ Este último tema ha sido desarrollado en Singer, Peter, The expanding circle - Ethics and Sociology, New York, Farrar, Straus \& Giroux. 
proclamados, en especial cuando alguien pueda sentirse lesionado por ellas.

Es así como los precios no se aumentan: se reajustan. Las empresas y los servicios no se reducen: se redimensionan. Las actividades públicas o privadas no se suprimen: se discontinúan. ${ }^{5}$ Occidente llega hasta el Japón; el cristianismo abarca al Dalai Lama, nuestro modo de vida incluye a Haití, pero no a Checoslovaquia. Y los deudores reciben una amable carta en la que, luego de informárseles con fingida sorpresa acerca de la existencia de un saldo en rojo, se los invita a regularizar la situación porque «de lo contrario nos veremos obligados a pasar el problema a nuestra Gerencia de Asuntos Jurídicos».

A esta última clase de disimulo quiero referirme ahora. A ella y al modo en que el lenguaje normativo contribuye a facilitarla. Para ese propósito emplearé algunos ejemplos de la historia política argentina.

\section{La coartada normativa, modelo 1955.}

Entre el 16 y el 19 de septiembre de 1955, el gobierno de la República Argentina fue depuesto por una revolución militar. Sea cual fuere el juicio político que se sustente sobre aquel gobierno y acerca del acto que le dio fin, vale la pena destacar la parte inicial del «discurso-programa» pronunciado por el jefe triunfante el 23 de septiembre: «El programa de mi acción provisional -que no tendrá más duración que la impuesta por las circunstancias- puedo resumirlo en dos palabras: Imperio del derecho». El 24, el nuevo presidente dictó el decreto n. ${ }^{\circ} 42$ que, entre otras cosas, decía:

«Que el triunfo con que la Providencia premió a las fuerzas de la Revolución selló su título al ejercicio del poder;

«Que el abandono del poder y de su supremo deber de comandancia por parte del Presidente de la Nación y Comandante en Jefe de las fuerzas armadas y la rendición incondicional que a ello se siguió, justifican el ejercicio de la pública potestad por parte del Jefe de la Revolución triunfante;

«Que la legalidad del alzamiento determinada por la intrínseca ilegalidad de los poderes depuestos ha sido confirmada por la expresa voluntad de recuperación jurídica proclamada en el Discurso-Programa leído al pueblo de la República en el acto de asunción del poder;

«Que es indispensable a la vida institucional del país asegurar el ejercicio ininterrumpido de los poderes previstos por la Constitución Nacional;

"Que cohonestando esta exigencia de continuidad con la situación de acefalía determinada por la revocación de los poderes preexistentes, se hace necesario que la función legislativa sea asumida por un poder

\footnotetext{
${ }^{5}$ Como puede verse, a menudo se emplean anglicismos que, con un prestigio inverso a su belleza, ayudan a enmascarar axiológicamente el sentido de las acciones.
} 
público que esté en condiciones de imponer en todo el territorio de la Nación la efectiva aplicación de sus mandatos;

«Por ello, el Presidente provisional de la Nación Argentina, decreta:

«Art. 10.- Mientras dure la situación de gobierno provisional definida en el Discurso-Programa leído en Buenos Aires al pueblo de la República en el acto de juramento del día 23 de septiembre del año en curso, el Presidente provisional de la Nación Argentina ejercerá las facultades legislativas que la Constitución Nacional acuerda...».

En el fragmento citado pueden observarse ciertos argumentos interesantes:

a) El título para el ejercicio del poder es otorgado por la divina providencia, y su manifestación visible es el triunfo de las armas;

b) La rendición o la huida de los vencidos justifican (y no sólo facilitan) el ejercicio del poder por el vencedor;

c) Existe una legalidad supra-legal cuya declaración no depende de los jueces y que permite declarar ilegales los poderes constitucionales y legal el alzamiento armado contra ellos;

ch) Tal legalidad del poder del jefe vencedor puede ser confirmada por los buenos propósitos declarados por el mismo jefe vencedor;

d) Quienes interrumpen el ejercicio de los poderes constitucionales pueden declarar como objetivo propio el ejercicio ininterrumpido de tales poderes;

e) El jefe triunfante asume la función legislativa, pero no por su mera voluntad sino porque la situación de acefalía (que él mismo determinó y declaró) lo hace necesario, ya que (debido a su propia acción) no hay otra autoridad capaz de hacer cumplir sus mandatos.

\section{Modelo 1962.}

En marzo de 1962 el presidente Arturo Frondizi fue depuesto por un golpe militar y encarcelado en la isla Martín García, en el Río de la Plata. Cuando el jefe rebelde, general Alejandro Poggi, se aprestaba a asumir el gobierno, la Corte Suprema dio un contragolpe puramente formal: tomó juramento al presidente provisional del Senado, José María Guido. Aunque las elecciones inmediatamente anteriores fueron anuladas y el Congreso disuelto, este funcionario se mantuvo en el cargo de presidente hasta las elecciones de 1963. De todos modos, no tenía posibilidad de oponerse frontalmente a los militares que lo toleraban, y debió suscribir un decreto (el n. ${ }^{\circ}$ 2877/62) que, en el marco del estado de sitio, disponía (esto es, convalidaba) la detención del ex presidente Frondizi... a disposición del Poder Ejecutivo. Así las cosas, la autoridad del nuevo presidente fue impugnada ante la Corte Suprema con fundamento en la Constitución Nacional, de la que sólo quedaba una ficción, por un ciudadano que solicitaba la reposición de Frondizi en su cargo. El tribunal decidió entonces que Guido era el presidente legítimo porque Frondizi se hallaba, de hecho, imposibilitado de ejercer su función. La circunstancia de que tal imposibilidad derivase (formalmente, es cierto) de una decisión del propio presidente que lo reemplazaba no pareció incomodar a los magistrados que de tal modo argumentaron: dijo el tribunal 
que la acefalía se configuraba ante la «falta de Presidente y Vicepresidente de la Nación», sin que incumba a la Corte Suprema pronunciarse acerca de la causa determinante de esa 'falta'»..$^{6}$

\section{Modelo 1966.}

El 28 de junio de 1966, un golpe militar terminó con el gobierno del presidente Arturo U. Illia. Los jefes de las tres armas firmaron primero un acta (el «Acta de la Revolución Argentina») por la que asumían el gobierno del país y explicaban los motivos que habían tenido para hacerlo, así como su determinación de transformar la nación en diversos aspectos políticos, económicos, sociales y aun morales, en cumplimiento de un mandato «histórico». Ese mismo día adoptaron diversas medidas, todas ellas precedidas de la fórmula: «... la Junta Revolucionaria, en ejercicio de sus propios poderes, decreta: «La destitución del Presidente y del Vicepresidente (decreto $n^{\circ}{ }^{\circ}$ ) se inicia con las palabras «Visto los arts. 2. ${ }^{\circ}$ y 3. ${ }^{\circ}$ del Acta de la Revolución Argentina». La intervención a las provincias (decreto n. ${ }^{\circ}$ 2) menciona: «Visto que por los arts. 2..$^{\circ}$ y $3 .^{\circ}$ del Acta de la Revolución Argentina han sido destituidos de sus cargos los gobernadores y vicegobernadores de todas las provincias, así como también disueltas sus legislaturas...». El cese de los miembros de la Corte Suprema de Justicia (decreto n. ${ }^{\circ}$ 3) lleva como antecedente «el art. 4. ${ }^{\circ}$ del Acta...». El artículo 3..$^{\circ}$ sirve para fundar el decreto n. ${ }^{\circ} 4$, que remueve al Intendente y disuelve el Concejo Deliberante de la ciudad capital; el artículo 5. ${ }^{\circ}$ sirve de antecedente normativo para disolver todos los partidos políticos (decreto n. ${ }^{\circ} 6$ ). Los artículos 9 y 10 de la fecunda acta operan como base para disponer que los nuevos jueces de la Corte Suprema sean designados por el Presidente de la Nación (que esta vez no se titula provisional). El decreto $\mathrm{n}^{\circ}{ }^{\circ} 8$, «visto lo dispuesto por el decreto $\mathrm{n}^{\circ} 2$ de esta Junta Revolucionaria», distribuye entre 23 oficiales de las fuerzas armadas los cargos de interventores provinciales. Y el decreto n. ${ }^{\circ}$ 9, «visto el art. 11 del Acta de la Revolución Argentina, y lo dispuesto en el art. 1. ${ }^{\circ}$ del Estatuto de la Revolución Argentina», designa Presidente al teniente general Juan Carlos Onganía.

Algo más tarde se dio a conocer el Estatuto de la Revolución Argentina (mencionado en los considerandos de los decretos 7 y 9), por el que se fijaban las atribuciones del nuevo gobierno y las de sus órganos. La fórmula utilizada aquí fue: «La Junta Revolucionaria, en ejercicio de sus propios poderes, estatuye: «Y de allí en adelante el jefe del Estado, investido del poder legislativo, dictaba tanto decretos («El Presidente de la Nación Argentina decreta») como leyes («El Presidente de la Nación Argentina, en uso de los poderes conferidos por el artículo 5. ${ }^{\circ}$ del Estatuto de la Revolución Argentina, sanciona y promulga con fuerza de ley»).»

${ }^{6}$ C.S.J.N., sentencia del 3/4/62 en autos «Pitto, Luis María s/petición» (Fallos de la Corte Suprema de Justicia de la Nación, vol. 252, pág. 178). 


\section{Modelo 1976.}

El siguiente gobierno constitucional fue depuesto por las fuerzas armadas el 24 de marzo de 1976. El nombre elegido para el período de facto que se iniciaba fue «Proceso de Reorganización Nacional», y el primer hecho normativo fue un acta firmada ante notario público. Luego del encabezamiento formal de rigor, los comandantes militares, «visto el estado actual del país, proceden a hacerse cargo del Gobierno de la República. Por ello, resuelven:

1. Constituir la Junta Militar con los Comandantes Generales de las FF.AA. de la Nación, la que asume el poder político de la República.

2. Declarar caducos los mandatos del Presidente de la Nación y de los gobernadores y vicegobernadores de las provincias».

Luego de otras disposiciones que, en un total de once puntos, disolvían el Congreso, removían a diversos funcionarios y establecían bases para el ejercicio futuro del poder (el punto 10 resolvía «designar, una vez efectivizadas las medidas anteriormente señaladas, al ciudadano que ejercerá el cargo de Presidente de la Nación»), el acta terminaba con un cierre de notable formalismo, literalmente copiado del Acta de 1966:

«Adoptada la resolución precedente se da por terminado el acto, firmándose cuatro ejemplares de este documento a los fines de su registro, conocimiento y ulterior archivo en la Presidencia de la Nación, Comando General del Ejército, Comando General de la Armada y Comando General de la Fuerza Aérea. Videla. Massera. Agosti».

El mismo día, los autores de aquel acta (mediante la fórmula «la Junta Militar estatuye») resolvieron suspender la vigencia del último párrafo del artículo 23 de la Constitución, que autoriza a los ciudadanos detenidos en virtud del estado de sitio a optar por salir del territorio nacional. Tal disposición es encabezada por estas palabras: «Visto lo dispuesto por la Junta Militar en el Acta para el Proceso de Reorganización Nacional...».

Días más tarde apareció el «Estatuto para el Proceso de Reorganización Nacional», suerte de reglamento de catorce artículos que establecía los órganos del poder militar y las atribuciones que cada uno de ellos tendría. Dicha pieza tiene el siguiente encabezamiento:

«Considerando que es necesario establecer las normas fundamentales a que se ajustará el Gobierno de la Nación en cuanto a la estructura de los poderes del Estado y para el accionar del mismo a fin de alcanzar los objetivos fijados y reconstruir la grandeza de la República, la Junta Militar, en ejercicio del poder constituyente, estatuye»:

Y el 27 de abril se «estatuyó» un artículo adicional sobre las atribuciones de los gobernadores provinciales, para lo que se usó la siguiente referencia: «Visto lo establecido en los artículos 12 y 14 del Estatuto para el Proceso de Reorganización Nacional».

Tres personas se atribuían el gobierno del país, comenzaban a ejercerlo, asumían el poder constituyente y disponían consecuentemente; pero, salvo en el Acta y en el Estatuto, cada uno de sus actos normativos contenía una referencia a actos anteriores, de los cuales el nuevo se presentaba como continuación o consecuencia. 


\section{Poder y pudor.}

Los ejemplos que anteceden provienen de golpes militares, pero el fenómeno que en ellos se observa no es privativo de los gobiernos de facto. Sin embargo estos muestran en forma condensada, sobre todo en sus momentos iniciales, la actitud del poder frente a las normas con una claridad que no se advierte en los períodos de larga tradición constitucional.

En el modo de relacionar la asunción del poder con la sanción de normas vale la pena señalar una evolución de los modelos reseñados. El de 1955 es en cierto modo ingenuo, en la medida en que no cobra conciencia de su autocontradicción. Extrae el poder de la voluntad divina (fuente última de legitimidad); y el paquete ético queda completado con las virtuosas intenciones de los vencedores. Pero al mismo tiempo el ejercicio del nuevo poder es legal (pretensión derivada de cierto sentimiento de veneración hacia el texto constitucional anterior). Lo es por dos motivos: la ilegalidad del régimen depuesto y la acefalía del gobierno por la rendición o la huida de quienes lo ejercían. El primero de dichos argumentos puede tener alguna fuerza política en el ánimo de los partidarios del nuevo gobierno, pero es jurídicamente dudoso si quienes lo invocan han derribado por las armas un poder electoralmente consolidado. El segundo argumento es políticamente débil (ya que sin el hecho revolucionario no habría acefalía), pero jurídicamente apoyado en precedentes judiciales (la Corte Suprema había elaborado esa doctrina a partir de 1930).

El modelo de 1962 no es ingenuo, sino todo lo contrario: tiene conciencia de su endeblez argumental pero insiste tercamente en disimular lo que está a la vista de todos. El poder proviene de la Constitución y se ejerce en su nombre; claro está que algunas desgraciadas circunstancias impiden momentáneamente el cumplimiento estricto de sus normas. Entre estas circunstancias se halla el encarcelamiento del Presidente, que justifica la asunción del cargo por su reemplazante legal; y también la nulidad de las últimas elecciones (dispuesta por el nuevo presidente), que obliga al Ejecutivo a disolver el Parlamento y a gobernar por decreto (hechos ambos que la Constitución no autoriza). En estas circunstancias es preciso mantener a toda costa el orden y la tranquilidad pública, y este alto propósito justifica disponer el arresto del anterior Presidente (arresto cuya concreción de hecho por los militares había servido antes de fundamento constitucional para la asunción del Poder Ejecutivo por el nuevo Presidente). El paquete (que esta vez no es ético, sino puramente «legal») es atado por prestigiosos juristas. Nadie cree en los argumentos que él contiene, ni están ellos destinados a ser creídos. Pero, en la conciencia de que se ha salvado al menos una pequeña parte del régimen civil, todos fingen desganadamente que los creen y la cuestión de si el gobierno del Dr. Guido es de facto o de iure queda siempre para ser debatida en un brumoso futuro.

El modelo de 1966 reniega por igual de la ingenuidad y de la ficción. Sus autores, que parecen tener una sólida formación kelseniana, prefieren dejar las cosas en claro. La Junta acuerda primero el Acta de la Revolución Argentina, donde queda explícitamente asentado el cambio 
de la norma básica: se «asume el poder político y militar de la República». De tal cambio se da cuenta al pueblo mediante un mensaje: «...era indispensable eliminar la falacia de una legalidad formal y estéril bajo cuyo amparo se ejecutó una política de división y enfrentamiento... de tal suerte que las Fuerzas Armadas, más que sustituir un poder, vienen a ocupar un vacío de tal autoridad y conducción antes de que decaiga para siempre la dignidad argentina». La misma junta ejerce luego el poder constituyente al promulgar el Estatuto de la Revolución Argentina. Y, cuando pone en ejecución lo acordado en el acta, la Junta obra «en ejercicio de sus propios poderes»; esto es en uso de un poder originario y no derivado de normas anteriores. Al disolverse la Junta, en cambio, el presidente militar legislará a su gusto pero como autoridad delegada, «...en uso de los poderes conferidos por el artículo 5. ${ }^{\circ}$ del Estatuto...».

En 1976 se siguió un esquema idéntico al de diez años antes: acta, estatuto, designación de presidente y ejercicio por éste de una autoridad derivada. Sólo cabe anotar, a modo de diferencias, cierto descuido de la estética normativa (agregados y reformas ulteriores del Estatuto) y variaciones en la estructura institucional (subsistencia de la Junta Militar, con reserva de ciertas atribuciones).

Pero, aun por encima de las diferencias o semejanzas que pueden observarse de un modelo a otro, se advierte una constante en la relación entre poder y norma. En efecto, quien ejerce el poder se siente desnudo frente a sus súbditos si no tiene alguna norma que ampare sus acciones. Por lo tanto, o bien invoca normas anteriores, acaso con cierto auxilio religioso (modelo 1955), o finge que su poder es el mismo que ejercían sus predecesores (modelo 1962), o da rápida expresión normativa a su poder y se apoya luego en esas normas, como si quisiera olvidar que fue él mismo quien las dictó (modelos 1966 y 1976). En estos últimos casos, ante la necesidad de hacer explícito el ejercicio inicial de un poder no derivado, sino conquistado de hecho, busca obsesivamente rodear ese acto de formalidades jurídicas, que llegan en 1976 al extremo de requerir la presencia de un escribano.

Acaso sea posible extraer de aquí una conclusión que, como dije antes, no se aplica sólo a los militares aunque señala un fenómeno particularmente observable en los gobiernos que se autoconstituyen. El poder es pudoroso. Se avergüenza de sí mismo. No tanto de las normas que dicta (que acaso puedan ser mejor o peor defendidas), como del hecho mismo de dictarlas.

No es difícil desentrañar de dónde proviene este pudor. El ejercicio del poder consiste siempre en imponer a las personas conductas, cargas o penas de las que es al menos dudoso que ellas las aceptasen de buen grado. Aun los actos que conceden beneficios suponen, en la mayoría de los casos, un costo para alguien; y la desaprobación o el disgusto de los afectados es una molestia que el poderoso no desea afrontar mediante la mera exposición de su preferencia axiológica. Es aquí donde aparece la tentación de trasladar al menos una parte de la responsabilidad.

En la época del absolutismo (me refiero al tiempo en que el absolutismo era ideológicamente aceptado: no al de su aplicación práctica que es aún el nuestro en muchos lugares), la responsabilidad se transfería, 
casi íntegramente, a una entidad supraempírica. El príncipe, que lo era «por la gracia de Dios», no debía a persona alguna cuenta de sus actos, y el precio que hubiese de pagar por ellos quedaba diferido al tiempo posterior a su muerte. En la actualidad, en cambio (y con excepción de ciertos estados teocráticos), se acepta que el poderoso, independientemente de que el origen de su poder sea democrático o autoritario, gobierna en beneficio del pueblo y debe satisfacer las aspiraciones de sus súbditos. El imperio de la ley, a menudo ensalzado como garantía contra el despotismo, suscita cierta actitud de veneración hacia las normas vigentes (aun con independencia de su contenido). Parece conveniente, en consecuencia, apoyarse siempre en alguna norma que pueda citarse con número de artículo; no sólo para fundar la propia capacidad legislativa sino también, en lo posible, para mostrar que la decisión que se adopta es consecuencia insoslayable de una norma preexistente (jurídica, moral o religiosa) a la que el decisor, simple amanuense al servicio de sus propias virtudes, debe acatamiento y obediencia.

En una primera aproximación, la tendencia que acabo de describir es seria candidata a un juicio desfavorable. En efecto, ella exhibe cierta inseguridad en la escala de los valores políticos y morales sustentada por quienes en cada caso ejercen el poder y, en especial, demuestra que la capacidad de hacerse obedecer no corre siempre parejas con el valor necesario para asumir públicamente la responsabilidad de acciones controvertidas.

Sin embargo, un análisis más minucioso que principista permite advertir que la tendencia al uso de la coartada normativa tiene un costado alentador.

Basta para ello considerar que el pudor del poder, el temor a confrontar el ejercicio del gobierno con la queja de los súbditos, la necesidad de justificación y, en especial, la búsqueda de esta justificación en la invocación de normas generales es precisamente el flanco débil del despotismo. Es el gran regalo que la Revolución Francesa, a despecho de involuciones posteriores, hizo al hombre de hoy. Un regalo que se exhibe, es cierto, en la organización de las sociedades democráticas; pero anida también, como molesto parásito, en el corazón de los tiranos. Es un medio débil pero persistente, del que disponen los súbditos para controlar y moderar la arbitrariedad de los gobernantes, ya que éstos no se sienten a gusto cuando se los sorprende incursos en acciones opuestas a las normas y a los valores en los que intentan justificar su poder.

En nuestros tiempos es posible incluso prever una evolución favorable a partir del actual disimulo, ya que la arbitrariedad tiende a hacerse técnicamente insostenible.

En efecto, la creciente complejidad de la vida social lleva insensiblemente (en especial con motivo del uso de la informática) al empleo de pautas generales, rutinas deliberadas y criterios formalizados. ${ }^{7}$ Esta

${ }^{7}$ Guibourg, Ricardo A., El fenómeno normativo. Buenos Aires, Astrea, 1987, págs. 147 y 148. 
aplicación obliga a hacer explícitos criterios que antes se hallaban encerrados -y protegidosen la caja negra de la apreciación discrecional; y, en la medida en que la necesidad administrativa y el avance tecnológico avancen de consuno por ese camino, será cada vez más difícil al poderoso escindir sus acciones de los valores que proclama. Que tales valores nos satisfagan no es algo que pueda garantizarse; pero, en el peor de los casos, pueden preverse mayor igualdad ante la ley, una seguridad jurídica más sólida y un mejor control público de las normas y de su aplicación.

Por esa vía el poder adquiriría mayor aceptabilidad intersubjetiva, en la medida en que su ejercicio se autolimitase y autoencauzase. Semejante evolución, aunque no incluyera otras mejoras, sería descrita por algunos como un avance de la justicia. 